\title{
New PTFE-based Material for Hydraulic Seal Applications
}

\author{
T. Larsen ${ }^{1}$, S. Roepstorff ${ }^{2}$, and H. Jordan ${ }^{3}$ \\ ${ }^{1,2}$ Trelleborg Sealing Solutions, R\&D, Helsingør, Denmark \\ E-mail: thomas.larsen@trelleborg.com, soeren.roepstorff@trelleborg.com, holger.jordan@trelleborg.com \\ ${ }^{3}$ Trelleborg Sealing Solutions, R\&D, Stuttgart, Germany
}

\begin{abstract}
PTFE-based materials are widely applied for seals and are chemically compatible with almost all media and tolerate a wide temperature range. The weaknesses of virgin PTFE are the wear and deformational properties, which however can be improved significantly by incorporating suitable fillers. A range of PTFE-based seal materials exists on the market today, each with their strengths and short-comings. The idea of a universally applicable seal material is probably unrealistic. However, this paper reports the outcome of a project aimed at developing a new PTFE-based material (Turcon ${ }^{\circledR} \mathrm{M} 12$ ), which covers a significantly wider range of applications compared to existing PTFE materials. Shown results compare this new material with traditional PTFE seal materials using different types of hydraulic test-rigs, operating conditions and media. The results show that the new PTFE material matches the good extrusion, wear and deformational properties of PTFE/Bronze while being able to cope with conditions of starved lubrication without damaging the counter surface.
\end{abstract}

Keywords: hydraulic seals, PTFE materials, test-benches, friction, wear, abrasiveness

\section{Introduction}

PTFE-based materials as a group are a well known standard for seal materials, which are applied in various hydraulic equipment [1-2]. PTFE is superior with respect to chemical and thermal resistance as well as low friction. Thus, PTFE is chemically compatible with almost all media and can operate in a wide temperature range [3]. The weaknesses of virgin PTFE are the wear and deformational properties. However, these properties can be improved dramatically by incorporating suitable fillers, which makes it possible to develop PTFE-based sealing materials with overall excellent properties.

Glass and bronze are widely applied as fillers for PTFE under well-lubricated conditions. PTFE/Glass fiber materials have high seal efficiency but moderate extrusion strength, and require a hard counter surface in order to avoid hardware damage due to the abrasiveness of glass fibers. PTFE/Bronze materials combine high extrusion resistance, high wear resistance and high seal efficiency, but in critical applications scratches can in principle be created in two different ways: 1) bronze is a relatively soft material but in demanding applications, a high contact temperature may lead to tribo-oxidation generating hard abrasive particles (sulphides and oxides) and 2) bronze particles may offer a good substrate for hard particles to attach to thereby increasing their grinding action.

Carbon/graphite particles and carbon fibers are widely applied fillers for PTFE under poorly lubricated conditions.
Carbon/graphite is mild against the counter surface, and depending on the specific filler type, a good extrusion resistance can be achieved. However, Carbon/graphite tends to suffer from a low wear resistance. PTFE/Carbon fiber materials typically have a good wear resistance but a lower extrusion resistance relative to PTFE/Bronze. PTFE/Carbon fibers maintain a porous surface in service, giving good lubrication of the contact area but also somewhat reduced seal efficiency.

In short, the typical fillers mentioned above all have their specific strengths and short-comings. Why, one might ask, should a new PTFE-based material be introduced to the market when a line of materials are available, which covers a wide range of applications? The answer: One sealing material, which combines the specific advantages of several existing materials, can bring a range of substantial advantages.

The task presented to R\&D was to develop a PTFE-based material for linear seals and scrapers, that would combine high seal efficiency with low friction, low wear on seal and hardware, as well as high extrusion resistance. On top of this it should not contain bronze, and be price-wise competitive. Needless to say this was no easy task, and it took years of analysis, testing and evaluation to develop the final candidate for field testing.

This paper shows several seal test results obtained with this new material Turcon ${ }^{\circledR}$ M12. The results are obtained using different types of test-rigs, which makes it possible to compare the performance with traditional seal materials 
based on the following parameters: friction, wear, deformation, extrusion, seal ability and hardware damage under well-lubricated and poorly lubricated conditions, respectively.

\section{Experimental}

Turcon $^{\circledR}$ M12 consists of a complex blend of reinforcing, wear-reducing and non-abrasive mineral fibers together with friction reducing additives. The nature of the fillers, the particle distribution of the applied fillers and the finial composition are carefully adjusted with the aim of obtaining the best balance between properties such as wear resistance, extrusion strength, seal efficiency, low friction, low abrasiveness and fatigue resistance. Specific fillers are typically capable of improving certain of the mentioned properties but at the expense of others. The same also applies to particle distributions and the degree of filling. Thus, the challenge has been to find a balance between these adjustable parameters in order to obtain the best overall performance.

Turcon ${ }^{\circledR}$ M12 is compared with traditional PTFE-based seal materials, which are shown in the table 1.

Table 1: traditional seal materials included for reference

\begin{tabular}{|c|c|c|}
\hline Material & Degree of filling & Abbreviations \\
\hline PTFE added pigment & Very low & PTFE/pigment \\
\hline $\begin{array}{c}\text { PTFE filled with } \\
\text { carbon fibers }\end{array}$ & Medium & PTFE/CF \\
\hline $\begin{array}{c}\text { PTFE filled with glass } \\
\text { fibers }\end{array}$ & Medium & PTFE/GF \\
\hline $\begin{array}{c}\text { PTFE filled with } \\
\text { bronze }\end{array}$ & Medium & PTFE/bronze \\
\hline $\begin{array}{c}\text { PTFE filled with } \\
\text { carbon particles }\end{array}$ & High & PTFE/carbon \\
\hline
\end{tabular}

The data presented in this paper are obtained using four different test-rigs, which will be briefly introduced in the following.

\subsection{Standard Rod-Seal Test}

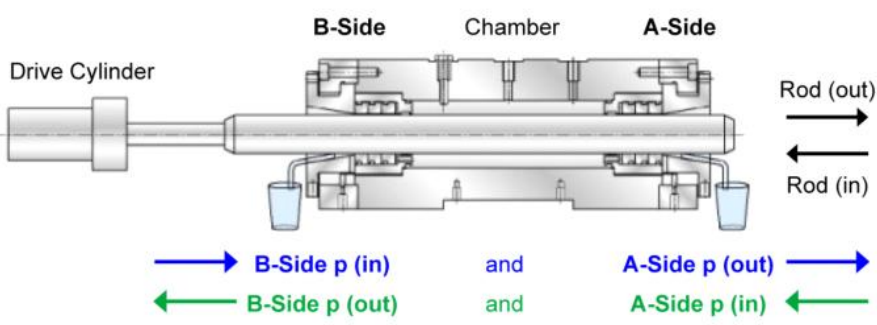

Figure 1: illustration of the applied Rod-Seal Test-Rig
Table 2: parameters applied for the standard rod-seal testing. Note, the A-side works as a rod seal normally operates

Test parameters:

Pressure cycle (A-side) $\quad: \mathrm{p}$ (out) $=<0.5 \mathrm{MPa}$

$\mathrm{p}($ in) $=30 \mathrm{MPa}$

Pressure cycle (B-side)

$: \mathrm{p}$ (out) $=30 \mathrm{MPa}$

$\mathrm{p}($ in) $=<0.5 \mathrm{MPa}$

Stroke length

: $280 \mathrm{~mm}$

Velocity

Rod

$0.20 \mathrm{~m} / \mathrm{s}$

: $\varnothing 50 \mathrm{~mm}$ hard chrome plated

Medium no. 1

: HV 46, Mineral oil, Equivis ZS

Medium no. 2

Temperature

Duration

: HEES 46, Ester oil, Biohydran

$: 55^{\circ} \mathrm{C}$

: 200,000 cycles $(112 \mathrm{~km})$

Test specimen

\subsection{Rod Seal Short Stroke / High Frequency Test}

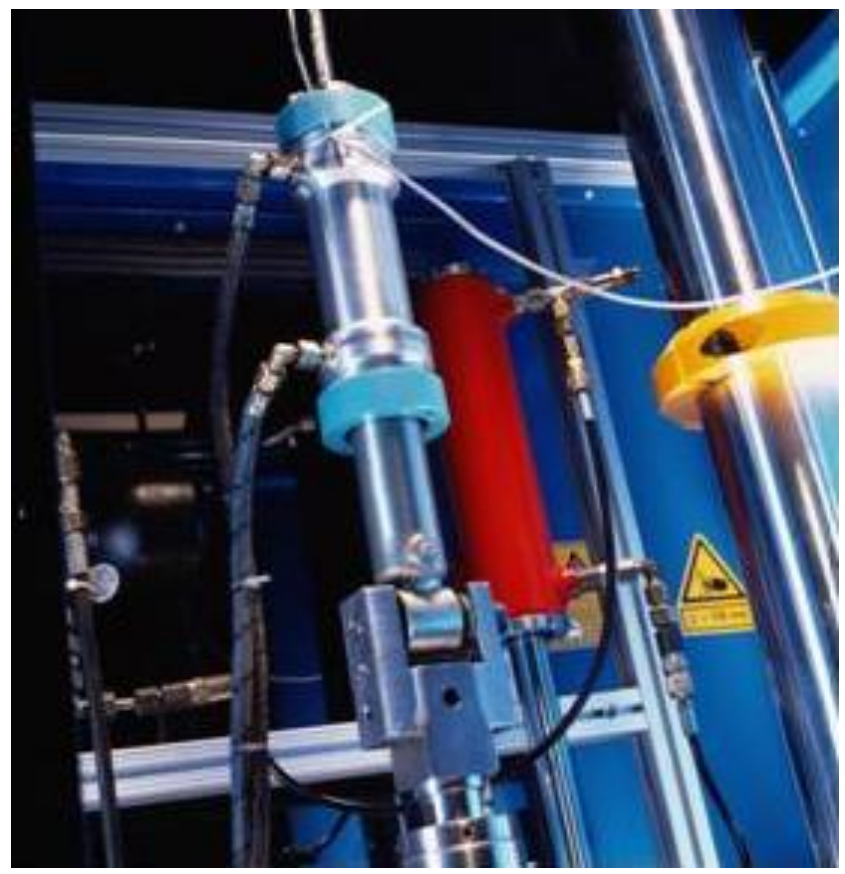

Figure 2: picture of the Hydro-Pulse (short stroke/high frequency) Test-Rig

Table 3: Parameters applied for the Hydro-Pulse (short stroke/high frequency) test

\begin{tabular}{ll}
\hline Test parameters: & \\
\hline Pressure & $: 15 \mathrm{MPa}$ (constant) \\
Stroke length & $: 5 \mathrm{~mm}$ \\
Frequency & $: 15 \mathrm{~Hz}$ \\
Temperature & $: 60{ }^{\circ} \mathrm{C}$ \\
Duration & $: 24 \mathrm{~h}(1.3$ million cycles $)$ \\
Medium & $:$ HLP 46, zinc free mineral oil, $46 \mathrm{cSt}$. \\
Test specimen & $:$ Rod seal, special Turcon ${ }^{\circledR}$ Twinseal \\
Rod & $: \varnothing 50 \mathrm{~mm}$ hard chrome plated steel \\
\hline
\end{tabular}




\subsection{Rod Seal Wear and Endurance Test}

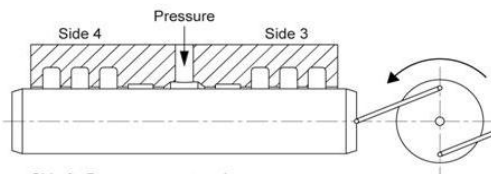

Side 3: Pressure on out stroke
Side 4: Pressure on in stroke

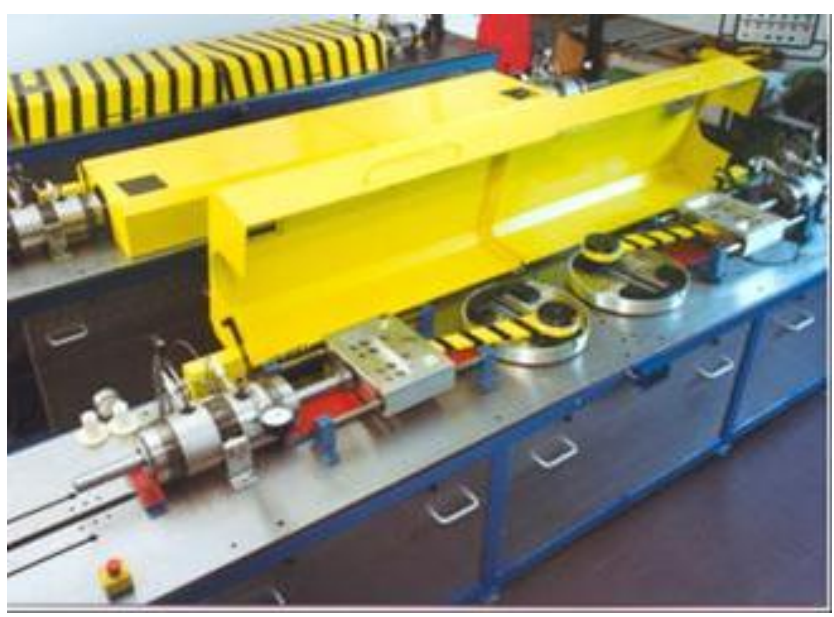

Figure 3: illustration (top) and picture (bottom) of the rod seal wear and endurance tester

Table 4: parameters applied for the rod seal wear and endurance tester

Test parameters:

\begin{tabular}{ll}
\hline Pressure & $: 20 \mathrm{MPa}$ (constant) \\
Stroke length & $: 10 \mathrm{~mm}$ \\
Velocity & $: 1 \mathrm{~Hz}$ \\
Rod & $: \varnothing 50 \mathrm{~mm}$ hard chrome plated steel \\
Medium & $:$ HLP 46, zinc free mineral oil, $46 \mathrm{cSt}$. \\
Temperature & $: 80^{\circ} \mathrm{C}$ \\
Duration & $: 1,000,000$ Cycles \\
Test specimens & $:$ Pri. rod seal Turcon ${ }^{\circledR}$ Stepseal ${ }^{\circledR} \mathrm{V}$ \\
& $:$ Sec. rod sealTurcon ${ }^{\circledR}$ Stepseal $^{\circledR} 2 \mathrm{~K}$ \\
\hline
\end{tabular}

\subsection{Side-Load Wear Ring Test}

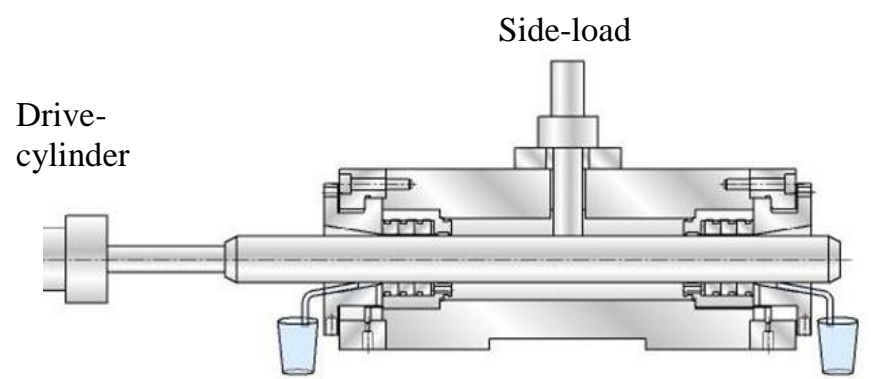

Figure 4: illustration of the side-load test-rig
Table 5: parameters applied for the side-load test

Test parameters:

Pressure $\quad: 2.5 \mathrm{MPa}$ (constant)

Side-Load $\quad: 8 \mathrm{~N} / \mathrm{mm}^{2}$ (on the wear rings)

Stroke length $\quad: 250 \mathrm{~mm}$

Velocity $\quad: 0.20 \mathrm{~m} / \mathrm{s}$

Rod $\quad: \varnothing 50 \mathrm{~mm}$ hard chrome plated steel

Medium :HV 46, Mineral oil, Equivis ZS, 46 cSt.

Temperature $: 50{ }^{\circ} \mathrm{C}$ (fluid temperature)

Duration $\quad: 100,000$ Cycles $(50 \mathrm{~km})$

Test specimen $\quad$ Wear rings, Slydring ${ }^{\circledR}$

\section{Results}

\subsection{Friction during Standard Rod-Seal Testing}

The friction data shown in this section is obtained using the standard rod seal test described in section 2.1. The friction values are for two rod seals at $30 \mathrm{MPa}$ and are shown as a function of the number of cycles completed.

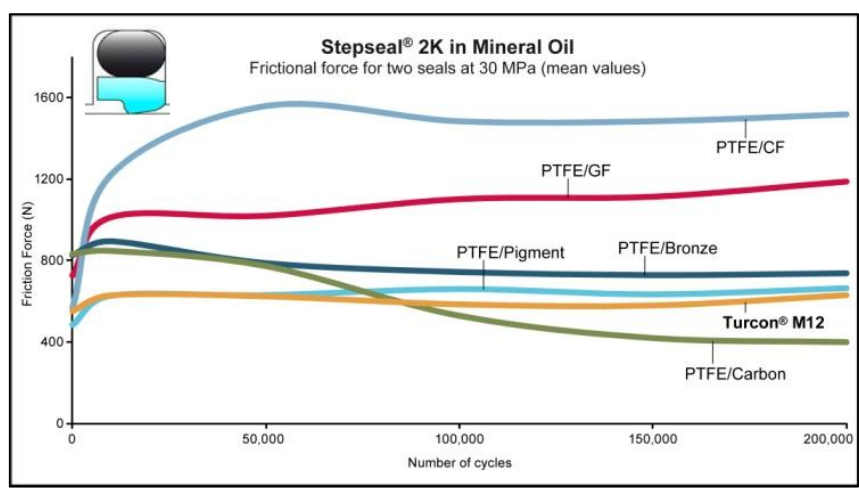

Figure 5: friction for two Stepseal ${ }^{\circledR} 2 \mathrm{~K}$ rod seals placed opposite each other in the same test-chamber. The hydraulic fluid is traditional mineral oil. Data is collected on the rod-seal test-rig described in section 2.1

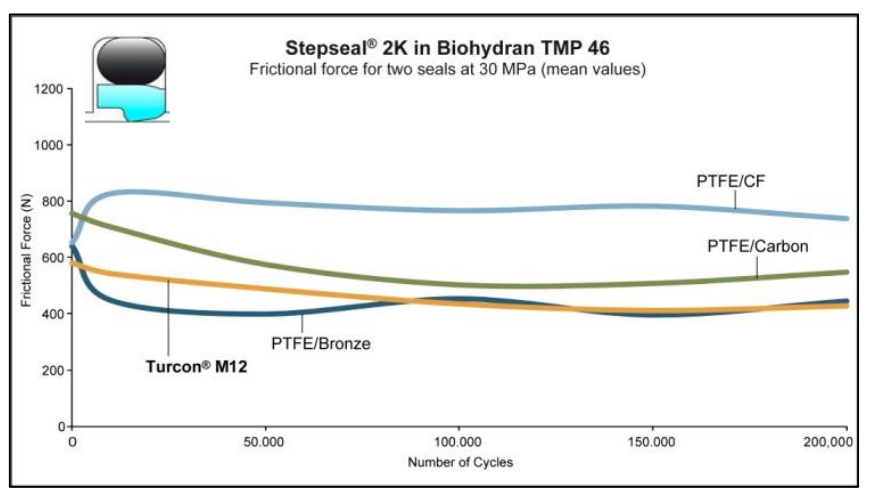

Figure 6: friction for two Stepseal ${ }^{\circledR} 2 K$ rod seals placed opposite each other in the same test-chamber. The hydraulic fluid is a bio degradable synthetic ester fluid. Data is collected on the rod-seal test-rig described in section 2.1 
Addition of fillers to PTFE typically increases friction, which is also seen in figure 5 when comparing the very low filled PTFE/pigment material with PTFE/CF, PTFE/GF and PTFE/bronze. Note that Turcon $^{\circledR}$ M12 has the same low friction as PTFE/pigment, which demonstrates the ability of the incorporated fillers to maintain a low level of friction. The friction of PTFE/carbon drops to a surprisingly low level after about 100,000 cycles, which is explained by a rapid increase in leak rate observed midway through the test. The Stepseal ${ }^{\circledR} 2 \mathrm{~K}$ rod seal test is repeated for some of the materials using a biodegradable fluid as medium instead of mineral oil, cf. figure 6 . Turcon ${ }^{\circledR} \mathrm{M} 12$ has lower friction than PTFE/carbon, which is normally recommended for fluids with reduced lubricity, and is on level with, but more stable than PTFE/bronze. PTFE/CF shows the highest friction, which was also the case when operating in mineral oil.

\subsection{Friction of Wear Rings}

Table 6 shows measured coefficients of friction when testing wear rings as described in section 2.4.

Table 6: coefficients of friction measured for Slydring ${ }^{\circledR}$ wear rings after 100 and 100,000 cycles, respectively. Data is collected on the side-load test-rig described in section 2.4

\begin{tabular}{|c|c|c|}
\hline Material & 100 cycles & 100,000 cycles \\
\hline Turcon $^{(\Theta)}$ M12 & $\mu=0.13$ & $\mu=0.14$ \\
\hline PTFE/carbon & $\mu=0.11$ & $\mu=0.18$ \\
\hline PTFE/CF & $\mu=0.08$ & $\mu=0.23$ \\
\hline PTFE/bronze & $\mu=0.15$ & $\mu=0.20$ \\
\hline
\end{tabular}

PTFE/CF shows the lowest run-in friction of the four tested materials. The coefficient of friction for Turcon ${ }^{\circledR}$ M12 has the same low value after 100,000 cycles as it had during run-in, whereas the friction for all the other materials increased significantly at the end of test.

\subsection{Leakage during Standard Rod-Seal Testing}

Rod seals are typically installed as systems rather than as single elements. At high system pressures the back-pumping ability of a single rod-seal may be hampered. Therefore, a secondary rod seal or a double-acting scraper is often installed behind the primary seal. This secondary seal operate at a lower pressure and will assist in maintaining hydrodynamic back-pumping and thus good seal-ability. Figure 7 shows the leakage behaviour for the two materials Turcon $^{\circledR}$ M12 and PTFE/Bronze when installed as a system consisting of two identical rod seals acting as a primary and a secondary seal, respectively.

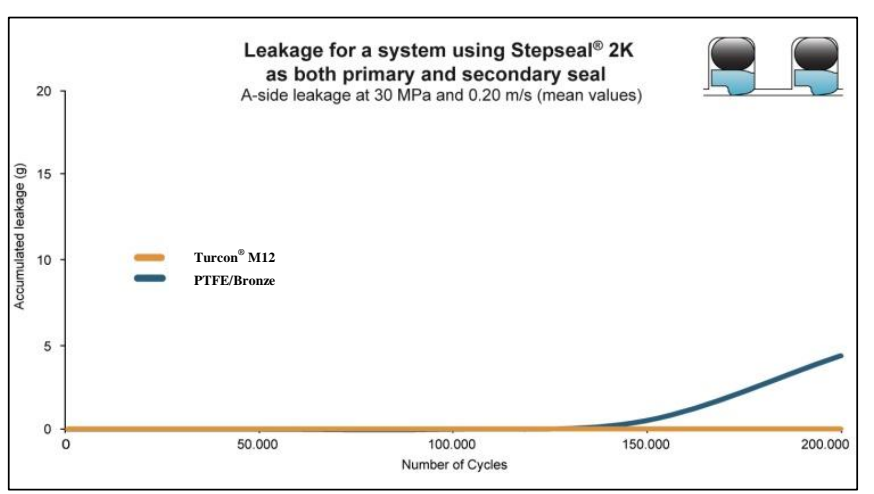

Figure 7: accumulated leakage versus the number of cycles completed for a seal system consisting of two Stepseal $^{\circledR} 2 \mathrm{~K}$ rod seals acting as a primary and a secondary seal, respectively. Data is collected on the rod-seal test-rig described in section 2.1

It is seen that the Turcon ${ }^{\circledR}$ M12 seal system is completely tight during the 200,000 cycles at $30 \mathrm{MPa}$. The PTFE/Bronze system also shows a good performance despite a small amount of leakage at the end of the test.

\subsection{Wear and Deformation of Wear Rings}

The reduction in w-measure (thickness) of wear rings after testing shows the combined effect of deformation and wear, cf. figure 8. It is seen that Turcon ${ }^{\circledR} \mathrm{M} 12$ has the lowest wear of the tested materials. The remaining (plastic) deformation is on the same level for Turcon ${ }^{\circledR} \mathrm{M} 12, \mathrm{PTFE} /$ bronze and $\mathrm{PTFE} / \mathrm{CF}$. The higher filled PTFE/carbon material has the lowest deformation but the wear is high, which is a frequently occurring weakness of this type of material.

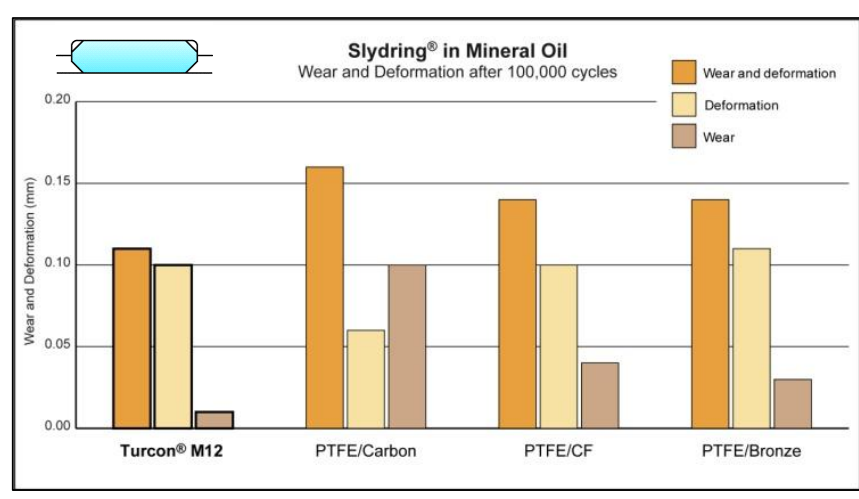

Figure 8: wear and deformation of Slydring ${ }^{\circledR}$ wear rings. In order to separate the contribution from wear and deformation, respectively, the tested wear rings have been resintered. During resintering the reduced thickness caused by deformation is recovered and the remaining reduction in thickness is due to wear. Data is collected on the side-load test-rig described in section 2.4

\subsection{Deformation and Wear of Rod-Seals}

Figure 9 shows the reduction of radial height of the seal profile (W) after testing, which is caused by deformation 
and wear. The lowest measured value is seen for Turcon ${ }^{\circledR}$ M12 both in mineral oil and in biodegradable oil. This result agrees well with the Slydring ${ }^{\circledR}$ test shown in figure 8 . In biodegradable oil the normally very wear resistant PTFE/bronze material clearly shows the highest wreduction. This high level is due to wear of the seals and indicates that the applied fluid does not have as high a lubricity as the applied mineral hydraulic oil.

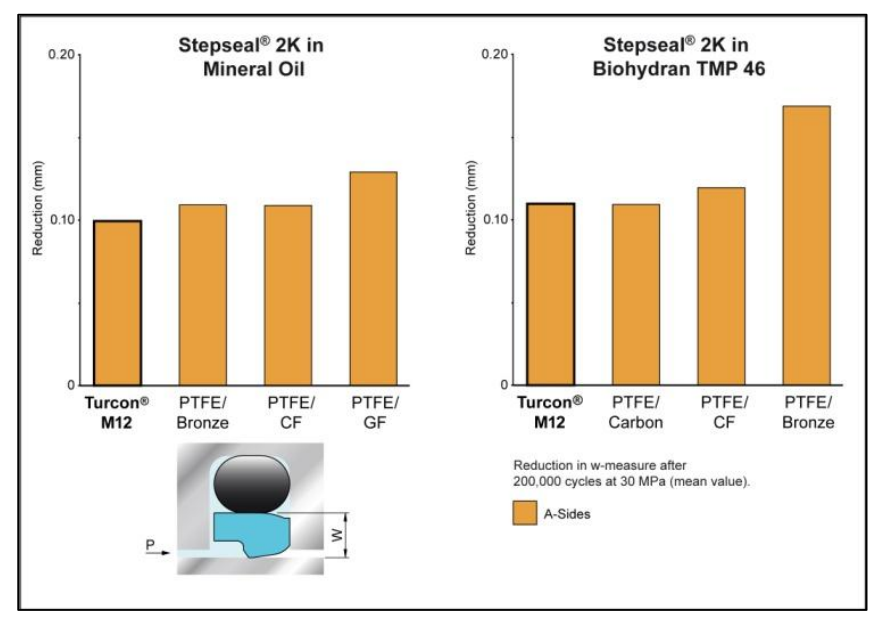

Figure 9: reduction of radial height of the seal profile, $W$ (a combination of deformation and wear) after testing in mineral oil and biodegradable oil, respectively. Data is collected on the rod-seal test-rig described in section 2.1

\subsection{Wear and endurance test of a rod seal system}

Figure 10 shows cross-sections and seal faces of the examined rod seal system after the wear and endurance test described in section 2.3. Furthermore, the roughnesses of the countersurface before and after testing are shown in figure 11. The short stroke movement combined with zinc free oil is considered especially critical from a lubrication and wear point of view. However, despite of this, the turning grooves from production of the seals can still be seen after one million cycles indicating a very low level of wear. The seal profiles look almost as new without any signs of extrusion. Furthermore, the roughness of the counter surface is basically unchanged. This shows a stable and constant tribosystem with long lasting potential.

\subsection{Extrusion of Rod-Seals}

The level of seal extrusion measured after the standard rod seal test (described in section 2.1) is shown in figure 12. In mineral oil, Turcon ${ }^{\circledR}$ M12 and PTFE/bronze have an equal performance, while PTFE/GF and PTFE/CF show higher extrusion. The lowest value is seen for the high filled PTFE/carbon. In biodegradable oil, the lowest extrusion is seen for PTFE/bronze but the fact that it also has the highest wear rate in this fluid may interfere with the result. Material at the contact surface, which could have extruded may be worn away. The extrusion of Turcon ${ }^{\circledR}$ M12 is close to the level seen for the high filled PTFE/carbon and significantly lower compared to PTFE/CF. secondary seal


primary seal
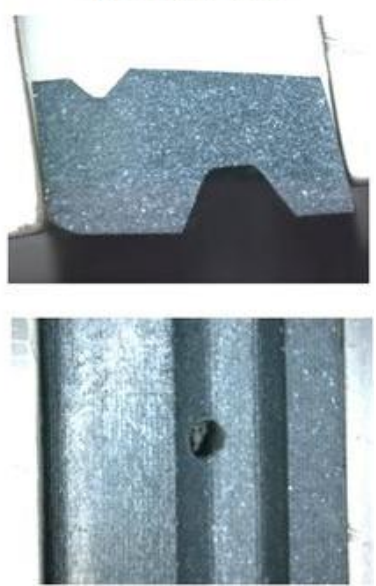

Figure 10: seal profiles (top) and seal faces (bottom) after wear and endurance testing shown for the primary and the secondary seal, respectively. Data is collected on the rod seal wear and endurance tester described in section 2.3
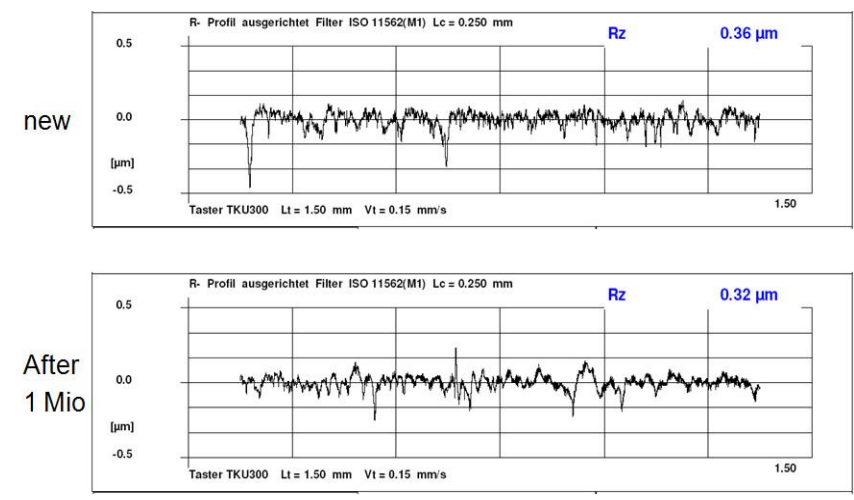

Figure 11: roughness of the hard chrome surface before and after wear and endurance testing

\subsection{Hardware Scratching - Hydro Pulse Test}

In order to compare the tendency of PTFE/bronze and Turcon ${ }^{\circledR}$ M12 to scratch the counter surface under poorly lubricated conditions, a test is conducted using short strokes, high frequency and Zinc free oil, cf. figure 13. In the case of PTFE/bronze, there are relatively heavy axial scratches at the complete seal contact area. This may be initiated by hard metal particles either released from the rod or present in the system, which subsequently get caught by bronze in the seal material and thereby accelerate wear on the rod. Tribooxidation may also play a role due to frictional heating. In the case of $\operatorname{Turcon}^{\circledR} \mathrm{M} 12$, a completely different result is obtained. Micro-scratching did not occur, and the grinding pattern from the manufacturing process of the rod is still visible even after 1.3 million strokes. Only a slight polishing of the metal surface has taken place. 


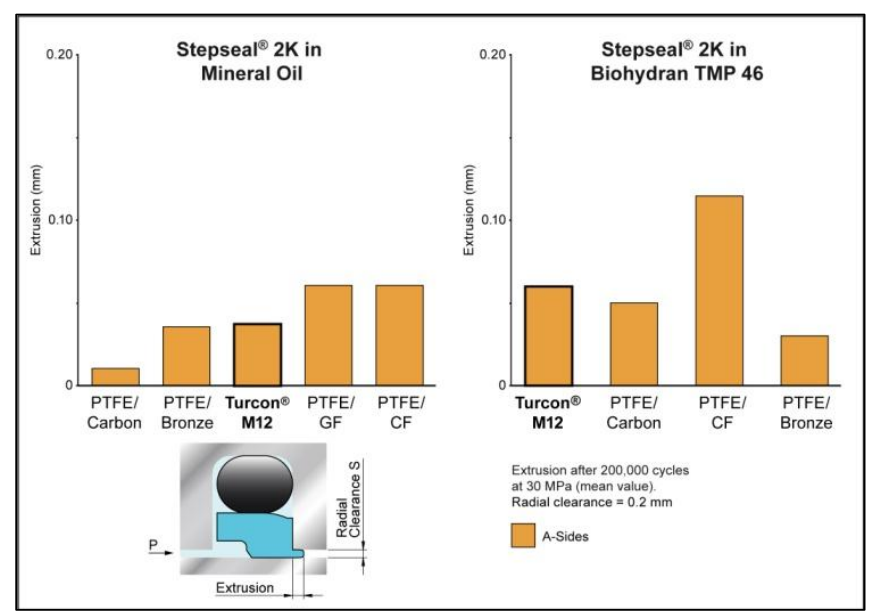

Figure 12: extrusion of Stepseal ${ }^{\circledR} 2 \mathrm{~K}$ rod seals in mineral oil and biodegradable oil, respectively. Data is collected on the rod-seal test-rig described in section 2.1
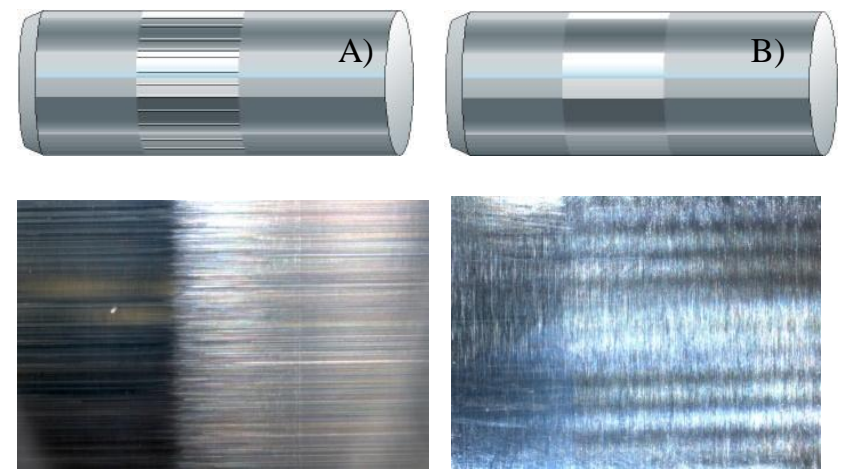

Figure 13: evaluation of micro-scratching after testing with short strokes and high frequency in Zinc free oil. Illustration (top) and picture (bottom) of the steel surface after testing: A) PTFE/bronze and B) Turcon ${ }^{\circledR}$ M12. Data is collected using the Hydro-Pulse test-rig described in section 2.2

\section{Conclusions}

The aim with this new PTFE-based material, Turcon ${ }^{\circledR}$ M12, has been to develop a material, which covers a significantly wider range of applications compared to existing PTFE materials. The results given in this paper show that Turcon ${ }^{\circledR}$ M12 matches the good extrusion, wear and deformational properties of medium filled bronze materials. The latter have limitations under conditions of starved lubrication or in media with reduced lubricity. Turcon ${ }^{\circledR}$ M12 is significantly better suited to cope with such conditions due to excellent wear properties and its ability to prevent damage to the counter surface. Furthermore, Turcon ${ }^{\circledR}$ M12 out-performs materials such as PTFE/carbon and PTFE/CF, normally recommended for fluids with reduced lubricity, on a number of parameters. Finally, both the wear ring test and the rod seal test shows that Turcon $^{\circledR}$ M12 is among the PTFE materials running with lowest friction.

\section{References}

[1] H K Müller and B S Nau. Fluid Sealing Technology Principles and Applications. Marcel Dekker, Inc. New York 1998, ISBN: 0-8247-9969-0

[2] R Flitney Seals and Sealing Handbook. ButterworthHeinemann, imprint of Elsevier, Oxford 2007, ISBN: 9781856174619

[3] S Ebnesajjad and P R Khaladkar. Fluoropolymers Applications in Chemical Processing Industries. William Andrew, Inc.2005, ISBN: 0-8155-1502-2 